\title{
An Analysis of the Causes and Countermeasures of the Phenomenon of "Marginal People" in Classroom Teaching at the Aspect of Teachers
}

\author{
Jiayi Wu \\ Zhejiang Ocean University, Zhoushan, 316000, China. \\ E-mail:310995182@qq.com
}

\begin{abstract}
The "Marginal People" in classroom teaching refer to those who are ignored or even excluded by teachers and other students because of their own reasons (physical and psychological differences) in classroom teaching activities. The "Marginal People" in classroom teaching are widespread, and their distribution areas are mainly concentrated in the edge of the classroom space, that is, the left and right sides and the back row, and it is more common in the classroom of teachers who do not pay attention to classroom interaction, boring lectures and straight intonation. The reasons for the emergence of marginal students are complex, among which teachers, as educators of the younger generation, need to bear a large part of the responsibility, such as: teacher literacy, teaching design, classroom management and other aspects of the impact on students. In the face of these problems, teachers should make corresponding adjustments and improvements.
\end{abstract}

Keywords: Teachers; Marginal People; Classroom Teaching

\section{The definition of "marginal people" in classroom teaching}

The prototype of marginal people theory comes from the concept of "stranger" put forward by German sociologist Georg Simmel in 1908, which is used to refer to those "people who live in a certain society but do not understand the internal mechanism of the society and are outside the social group" [ Robert E. Parker, an American sociologist, further put forward the concept of marginal people: from the perspective of describing the phenomenon of immigration and cross-cultural conflict, he believes that marginal people are "people on the edge of two cultures and two societies, and these two cultures and two societies have never been completely infiltrated and integrated." In his eyes, marginal people are "anxious, maladjusted, eager to be members of a new group but excluded" []. American scholar Frank. E. Williams also established five criteria for the selection of marginal students from the perspective of educational ecology: (1) low IQ; (2) poor academic performance; (3) father's occupation is not a professional profession; (4) father did not graduate from high school; (5) mother did not graduate from high school. The students who meet the above conditions are basically marginal students ${ }^{[}$. However, Chinese scholars believe that "marginal students generally refer to those students who lack the ability and background to promote academic success, and also refer to those students who are in a disadvantageous position in school" "]

Based on the above analysis, this paper defines the classroom "marginal people" as individuals or groups who are ignored or even excluded by teachers and other students due to their own reasons (physical and psychological differences) in classroom teaching activities.

\section{An analysis of the present situation of "marginal people" in classroom teaching}

Copyright (C) 2020 Jiayi Wu

doi: $10.18282 /$ le.v9i7.1526

This is an open-access article distributed under the terms of the Creative Commons Attribution Non-Commercial License

(http://creativecommons.org/licenses/by-nc/4.0/), which permits unrestricted non-commercial use, distribution, and reproduction in any medium, provided the original work is properly cited. 
There are mainly the following current situations in classroom teaching: (1) "Marginal People" are common in classroom teaching. In classroom teaching, it is an indisputable fact that "Marginal People" are widespread. (2) The distribution area of marginal people is mainly concentrated in the edge of the classroom space, that is, the left and right sides and the back row. (3) The marginal number of teachers who do not pay attention to classroom interaction, boring lectures and straight intonation are more than those who emphasize classroom interaction, humorous lectures and changeable intonation. The existence of "Marginal People" runs through the whole process of our learning career. Perhaps at the beginning of enrollment, they are also happy to participate in teaching, but with the passage of time, due to various reasons, they begin to stay away from classroom teaching and become invisible people outside teaching. Many teachers say there is nothing they can do about this, and "Marginal People" also have different attitudes and feelings towards their own living situation. Some have acquiesced to their own marginal state, while others linger on the marginal line. In a word, the phenomenon of "Marginal People", as an objective existence, has a negative impact on the socialization development of students. If it cannot be paid attention to, it will bring serious harm to the individual development of students. []

\section{The reasons for the formation of "marginal people" in classroom teaching}

The reasons for the emergence of marginal students are complicated, among which teachers, as educators of the younger generation, need to bear a large part of the responsibility. The following is to talk about the impact on the formation of marginal students from the perspective of teachers.

\subsection{The influence of teachers' accomplishment}

Teachers' professional accomplishment includes professional ability and professional knowledge, and higher professional accomplishment is one of the guarantees of teachers' authority. Teachers with high professional quality have noble professional ideals and firm professional beliefs. They pour all their painstaking efforts into training the next generation, unreservedly contribute their energy, talents and knowledge, and not only care about students' study, mind and body, but also love all students equally and treat each student fairly and justly. Such teachers can stimulate students' love, gratitude and trust to teachers, so that students are willing to get close to teachers and receive teachers' education, so as to develop a good relationship between teachers and students, create a good classroom atmosphere, and promote the harmonious development of students. However, most university teachers do not carry out systematic induction training and often fail to meet the above standards. Most of them regard teaching as a task and only care about the study of students, or even the study of top students. This will only make the relationship between teachers and students and student-student relationship more tense, which is not conducive to the harmonious development of students. Some teachers still cling to the traditional education view, teaching view, teacher-student view, accustomed to the traditional mode of practice, do not pay attention to and do not really realize the importance of students' initiative, autonomy and creativity, but also lack of experience, methods and ability, simple and boring teaching content makes some students will be in the classroom, not in learning, which leads to the gradual marginalization of students.

\subsection{The influence of instructional design}

Teaching design is that teachers make plans and arrangements for teaching objectives, teaching contents, teaching strategies and teaching media before teaching according to students' age characteristics and learning needs, guided by certain teaching goals and using scientific and systematic methods. With the development of science and technology, multimedia has been widely used in schools. However, this also leads to teachers relying too much on multimedia courseware to present knowledge. Teachers rarely move in the classroom, focusing mainly on the students in front of them and pay no attention to the students in the back row and the side. When teaching, teachers often adopt different teaching strategies to produce different effects. Excellent teachers will adopt appropriate strategies when teaching. If they adopt inappropriate strategies in the classroom, for example, if they present too much new knowledge in a short period of time or the teaching content is not organized and logical ${ }^{[]}$, it will make it more difficult for students to accept new knowledge and even give up. All these signs show that instructional design is an important part of teaching, and if there are problems in the design, it will accelerate the emergence of marginal people. 


\subsection{Classroom management}

There are three types of styles in class management: autocratic, laissez-faire and democratic. Autocratic teachers like students to obey their own orders, and they are prone to anger, criticism, intimidation or abuse to those who do not obey, and students naturally always feel fear in front of such teachers. In short, laissez-faire teachers are unwilling to be responsible or give up performing their duties because of their limited professional quality and inability to manage the classroom well. Democratic teachers agree that they are equal to their students. Such teachers are good at listening to other people's criticisms and actively adopt reasonable suggestions. ${ }^{[1}$ It is obvious that the third type of teachers not only respect and love their students, but also perform their duties perfectly, and the management style of the first two types of teachers makes it easy to produce marginal people in the class.

\section{Suggestions on "marginal people" in classroom teaching}

\subsection{The training and improvement of teachers}

Teachers' accomplishment is directly related to the success or failure of educational work, which is not only the basis for teachers to establish prestige in the eyes of students, but also an important reason for the great difference in teachers' labor value. Although the problem of the number of teachers in basic education in China has basically been solved and the teaching quality has been significantly improved, however, there are still some concerned and worrying problems, such as the imbalance of teachers' distribution and structure, the imbalance of teachers' quality, the instability of teachers, and the lack of modern educational consciousness and ability of some teachers. Therefore, it is urgent to train and improve teachers. The main ways to train, expand and improve teachers are: strengthening and reforming normal education, implementing teacher qualification inspection system, strengthening teachers' in-service education and so on.

\subsection{Improve teaching design}

Teaching design should be carried out closely around four basic elements: What is the expected goal of teaching? In order to achieve the expected goal, what kind of knowledge and experience should be chosen? How to organize effective teaching? How to get the necessary feedback? And according to the teaching design reasonable arrangement of teaching objectives, teaching content, teaching time, teaching measures, teaching evaluation and so on. Choose reasonable and diverse teaching methods and strategies when teaching. For example, when teaching, teachers should have accurate meaning, appropriate words and moderate speed; when asking questions, the questions should be clear, the wording should be accurate, specific and clear, and so on. ${ }^{[]}$

\subsection{Strengthen classroom management}

In class management, we should give full play to the educational role of class collective, cultivate collective consciousness and collectivist emotion, cultivate students' ability and skills to organize and manage collective, and cultivate students' habit of consciously abiding by discipline. Teachers should assume their own responsibilities, teachers as the guardians of students' growth: they should always pay attention to the development of class members in all aspects, so that classroom activities can run on a normal track; teachers are also the guides of students' development: teach students to learn to be human and do things, and rely on their own prestige to stimulate students to receive education and form the ability of self-education. Teachers should also help to create a healthy, progressive, rich and active class cultural environment, including interpersonal environment, correct public opinion and class style, healthy psychological environment and so on. ${ }^{[]}$

\section{Conclusion}

The phenomenon of "Marginal People" is an extremely complex problem. Although their emergence is closely related to teachers' teaching and management, it is not only a teaching problem, and it cannot be treated simply with teaching theory. The emergence of "Marginal People" also covers many aspects, such as society, culture, psychology and so on. Therefore, it is necessary to put the "Marginal People" in a broader perspective to explore its generation mechanism. At the same time, we also adopt a positive attitude towards "marginal people", and believe that we can help 
them transform through teaching means and methods. The transformation process of "Marginal People" must be a long process, although they cannot change the social environment, family and cultural environment, but the correct teaching methods can also help them out of the "quagmire". In other words, teachers can reduce the emergence of "Marginal People" and accelerate the transformation of "Marginal People" by training and improving teachers' accomplishment, improving teaching design, strengthening classroom management and other means. This paper is devoted to reducing the occurrence of "Marginal People" and hoping to help "Marginal People" return to normal teaching activities.

\section{References}

1. Qiu D. The formation of "edge students" and transformation strategies. Journal of Qiannan Normal University for Nationalities 2013; (1): 56-59.

2. Zhang L. Changes The evolution of American marginal theory (in Chinese). Journal of Tianzhong 2010; (4): 64-67.

3. Fan G. Educational ecology (in Chinese). Beijing: People's Education Press; 2000. p. 230, 231.

4. Brewer BL. Interracial marriage: American men who marry Korean women [PhD thesis]. Syracuse University; 1982.

5. Zhou J. The phenomenon of "marginal person" in classroom teaching [MSc thesis]. Tianshui: Tianshui Normal University; 2019. p. 1-50.

6. Jointly compiled by twelve key normal universities across China. Fundamentals of education (in Chinese). Beijing: Educational Science Publishing House; 2014. p. 230.

7. Jointly compiled by twelve key normal universities across China. Fundamentals of education (in Chinese). Beijing: Educational Science Publishing House; 2014. p. 299.

8. Wang D, Guo W. Education (in Chinese). Beijing: People's Education Press; 2016. p. 404-410.

9. Jointly compiled by twelve key normal universities across China. Fundamentals of education (in Chinese). Beijing: Educational Science Publishing House; 2014. p. 226-234.

10. Jointly compiled by twelve key normal universities across China. Fundamentals of education (in Chinese). Beijing: Educational Science Publishing House; 2014. p. 300-313. 